\title{
A Novel Processing for CNT-Reinforced Mg-Matrix Laminated Composites to Enhance the Electromagnetic Shielding Property
}

\author{
Wanshun Zhang ${ }^{1}$, Hongyang Zhao ${ }^{1, *}$, Xiaodong $\mathrm{Hu}^{1}$ and Dongying $\mathrm{Ju}^{1,2}$ \\ 1 School of Material and Metallurgy, University of Science and Technology Liaoning, Anshan 114051, China; \\ aswanshun@163.com (W.Z.); mjfoil@163.com (X.H.); dyju@sit.ac.jp (D.J.) \\ 2 Saitama Institute of Technology, Fusaiji 1690, Fukaya 369-0293, Japan \\ * Correspondence: zhy@ustl.edu.cn
}

Citation: Zhang, W.; Zhao, H.; $\mathrm{Hu}$, X.; Ju, D. A Novel Processing for CNT-Reinforced Mg-Matrix

Laminated Composites to Enhance the Electromagnetic Shielding Property. Coatings 2021, 11, 1030. https://doi.org/10.3390/ coatings11091030

Academic Editor: Alina Pruna

Received: 20 July 2021

Accepted: 25 August 2021

Published: 27 August 2021

Publisher's Note: MDPI stays neutral with regard to jurisdictional claims in published maps and institutional affiliations.

Copyright: (c) 2021 by the authors. Licensee MDPI, Basel, Switzerland. This article is an open access article distributed under the terms and conditions of the Creative Commons Attribution (CC BY) license (https:// creativecommons.org/licenses/by/ $4.0 /)$.

\begin{abstract}
The microstructure, electrical conductivity, and electromagnetic interference (EMI) shielding effectiveness (SE) of CNTs/Mg Matrix composites prepared by accumulative roll bonding (ARB) were systematically investigated to understand the effects of CNTs on the electromagnetic interference shielding effectiveness property of magnesium. A model based on the shielding of the electromagnetic plane wave was used to theoretically discuss the EMI shielding mechanisms of ARB-processed composites. The experimental results indicated that the methods were feasible to prepare laminated composites. The SE of the material increased gradually with the increase of electrophoretic deposition time. When the electrophoretic deposition time reached $8 \mathrm{~min}$, the value of SE remained $87-95 \mathrm{~dB}$ in the frequency range of 8.2-12.4 GHz. The increase in SE was mainly attributed to the improvement in the reflection and multiple reflection losses of incident electromagnetic wave due to the increased amounts of CNTs and interfaces. The methods provided an efficient strategy to produce laminated metal matrix composites with high electromagnetic shielding properties.
\end{abstract}

Keywords: carbon nanotubes; magnesium matrix composites; accumulative roll bonding; electromagnetic shielding property

\section{Introduction}

With the rapid popularization of electronic equipment and the continuous improvement of the utilization rate, electronic noise, electromagnetic interference(EMI) and radio frequency interference, other electronic pollutions increase sharply [1,2], which will lead to the abnormal operation of electronic equipment and harm human health [3-5]. Therefore, EMI has become a matter of concern, especially in the field of $3 \mathrm{C}$ and electrical apparatuses [6]. In order to ease the pollution of electromagnetic interference, it is imperative to develop EMI shielding materials [7]. However, traditional metal materials, such as copper, nickel, and permalloy have the drawback of their heavy weight [8,9]; polymer composites are light in weight, but they suffer in terms of their cost and low strength [10-13], so they cannot be used as structural materials; and coats materials are easy to shed. Therefore, it is urgent to develop light weight and cost-effective shielding materials, especially in portable electronics and aerospace industries [8].

Magnesium possess low density, high specific stiffness, high specific strength, excellent damping capacity, recyclability, and easy fabrication [14-16] while also possessing good electromagnetic shielding property [5]. At present, most of the researches on the electromagnetic shielding properties of magnesium with rare earth (RE) have already been carried out $[3,5,9,17,18]$. For example, Chen et al. explored the different $\mathrm{Nb}$ contents on the electromagnetic interference (EMI) shielding properties of an $\mathrm{Mg}-\mathrm{Y}-\mathrm{Zr}-\mathrm{Nd}$ alloy, and it was found that the EMI shielding effectiveness of the alloy could be improved by the precipitated second phases of Mg24Y5, Mg41Nd5, and $\beta$ phase with a Mg41Nd5Y composition [3]; Liu et al. reported that Ce addition induced the formation of the $\mathrm{Mn}-\mathrm{Zn}-\mathrm{Ce}$ 
phase, which was beneficial to improve the SE [19]. However, the addition of RE increased the cost and density.

As is known to all, Carbon nanotubes (CNTs) are ideal metal-matrix reinforcers, which possess extremely high elastic modulus and strength, as well as thermal, electrical and absorbed properties [20-24]. CNTs could be deposited on substrates by the electrophoretic deposition (EPD) process, which is an effective method; as well, the thickness of CNTs can be controlled [25-27]. The accumulative rolling bonding (ARB) process is not only a traditional rolling deformation method, but also a metallurgical diffusion welding process $[28,29]$. The process can manufacture ultra-fine grain materials and is a low cost, simple process. In the experiments, we produced the magnesium matrix composites with good electromagnetic shielding by the method; it could weld the adjacent layers and disperse CNTs evenly, resulting in a layered structure with the increase of rolling passes. When this occurs, the number of interface layers will increase rapidly.

In this paper, $\mathrm{CNTs} / \mathrm{Mg}$ matrix laminated composite materials were designed and produced by the ARB process. The EMI SE of composites were investigated in the X-band frequency range. In general, the reaches were expected to lead to new insights into design a lightweight shielding material providing radiation protection.

\section{Experimental Methods}

The fabrication process of the CNT-reinforced Mg-matrix laminated composites was shown in Figure 1. The five main procedures were included. (1) The CNTs was acidizing treatment; (2) the CNTs were deposited on Mg plates by electrophoretic deposition (EPD); (3) the plates were stacked in the order; (4) the stacked plates were warmly rolled; and (5) the rolled plates were cut into equal parts and then rolled again.

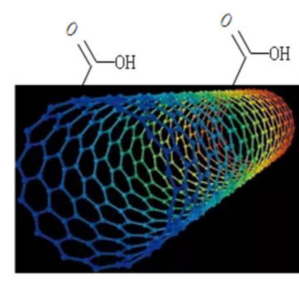

Acidification Treated CNTs

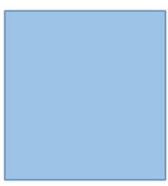

$\mathrm{Mg}$

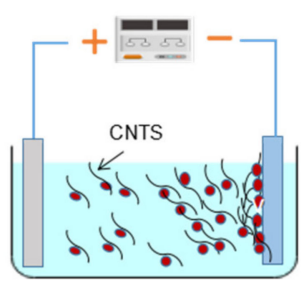

EPD Process

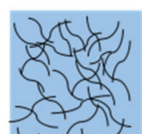

$x=2 x$

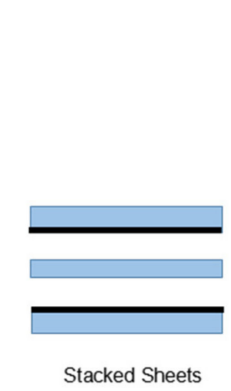

Stacked Sheets
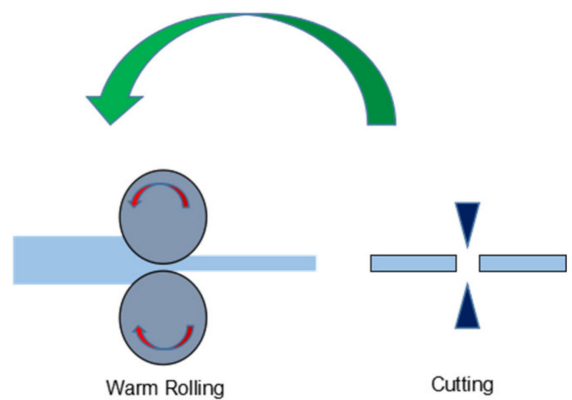

Cutting

Figure 1. Schematic illustration for the preparation of composite materials with layered structure.

Commercially pure magnesium (99.95 wt.\%), with a thickness of $0.5 \mathrm{~mm}$, and multiwalled CNTs (inner diameter: 2-10 nm, outer diameter: 20-40 nm, length: 10-30 $\mu \mathrm{m}$ ) were purchased from the Shanghai Aladdin Biochemical Technology. The specifications of all the chemicals are analytical pure. Van der Waals forces exist between the carbon nanotubes, which could cause aggregation of carbon nanotubes. Therefore, CNTs were added to the mixture of $\mathrm{HNO}_{3}$ and $\mathrm{H}_{2} \mathrm{SO}_{4}$ (1:3 volume ratio), after ultrasonic treated for $30 \mathrm{~min}$, the slurry was stirred for $6 \mathrm{~h}$ at $70{ }^{\circ} \mathrm{C}$, then place into the dialysis bag which was dialyzed by distilled water until the $\mathrm{PH}$ reached 7. Subsequently, the slurry was dried at $110^{\circ} \mathrm{C} .0 .04 \mathrm{~g}$ of surfaced treated CNTs and $0.08 \mathrm{~g}$ of $\mathrm{Al}\left(\mathrm{NO}_{3}\right)_{3}$ were dispersed into $1000 \mathrm{~mL}$ alcohol and then ultrasonic treated for $4 \mathrm{~h}$. Finally, the CNTs aqueous dispersion were obtained. CNTs were deposited onto $\mathrm{Mg}$ sheets by EPD process and the layer elements of the composites were prepared. $\mathrm{Mg}$ sheets $110 \times 60 \times 0.5 \mathrm{~mm}$, which were cleaned by the steel ball, washed by alcohol. Then the sheets were served as the cathode. The stainless-steel sheet was adopted as the anode. The distance of the two electrodes was arranged as $50 \mathrm{~mm}$, and the 
voltage was $60 \mathrm{~V}$. By changing the deposition time, the amount of CNTs deposited on the magnesium plate was varied, in this experiment, the time of EPD was arranged as $0 \mathrm{~min}$, $4 \mathrm{~min}$, and $8 \mathrm{~min}$ (named the materials I-III) respectively. In the ARB process, the reduction was $50-60 \%$ per pass, with the rolling temperature of $270{ }^{\circ} \mathrm{C}$, in the middle of each pass, the materials were annealed at $300^{\circ} \mathrm{C}$ for $5 \mathrm{~min}$. After the initial bonding, the materials were rolled three times by ARB. The schematic of ARB process was shown as Figure 1. Finally, CNTs/Mg matrix materials with laminated structure were produced.

Microstructures were observed by optical microscopy (OM) (ZEISS, Jena, Germany). The microstructures and fracture surfaces of $\mathrm{Mg}$ and composites were performed by scanning electron microscopy (SEM) (ZEISS, Jena, Germany). Raman spectra were utilized to analyze the structure characteristics of CNTs with a $532 \mathrm{~nm}$ wavelength laser (JOBIN YVON, Paris, France). The phase determination was carried out with X-ray diffractometer (XRD) (PANalytical B.V, The Netherlands). The electrical conductivity of the composites was evaluated utilizing Sigma 2008B conductivity meter (Tianyan, Xiamen, China), and each conductivity value was the average of five tests. EMI SE was determined in the X-band (8.2-12.4 GHz), which using the standard coaxial cable method in accordance with ASTM D4934-2010 (Dinrong, Beijing, China) [7], the samples in a square form with $41.4 \times 41.4 \mathrm{~mm}$, and $0.5 \mathrm{~mm}$ in thickness.

\section{Results and Discussion}

\subsection{CNTs Dispersion}

As shown in Figure 2. The raw CNTs agglomerated in large clusters. After acidification, the process was conducive to dispersion, and it is known that the acidification process could overcome the Van der Waals force between CNTs [30-33], which was conducive to dispersion. However, the multilayer structure of CNTs could be damaged during acidification process. It was well known that the Raman spectra provided information regarding the quality of the internal CNTs [34,35]. From the Raman spectra results in Figure 3 , the intensity ratio $\left(\mathrm{I}_{\mathrm{D}} / \mathrm{I}_{\mathrm{G}}\right)$ of disordered-band (D-band) near $1350 \mathrm{~cm}^{-1}$ to the graphite-band (G-band) near $1590 \mathrm{~cm}^{-1}$ was known to provide information on the structure of CNTs, the minor difference between these $\mathrm{I}_{\mathrm{D}} / \mathrm{I}_{\mathrm{G}}$ values indicated that the $\mathrm{CNT}$ structure was hardly damaged during the fabrication process, the values indicated that the process was attributed to the introduction of the functional groups which was beneficial to EPD.
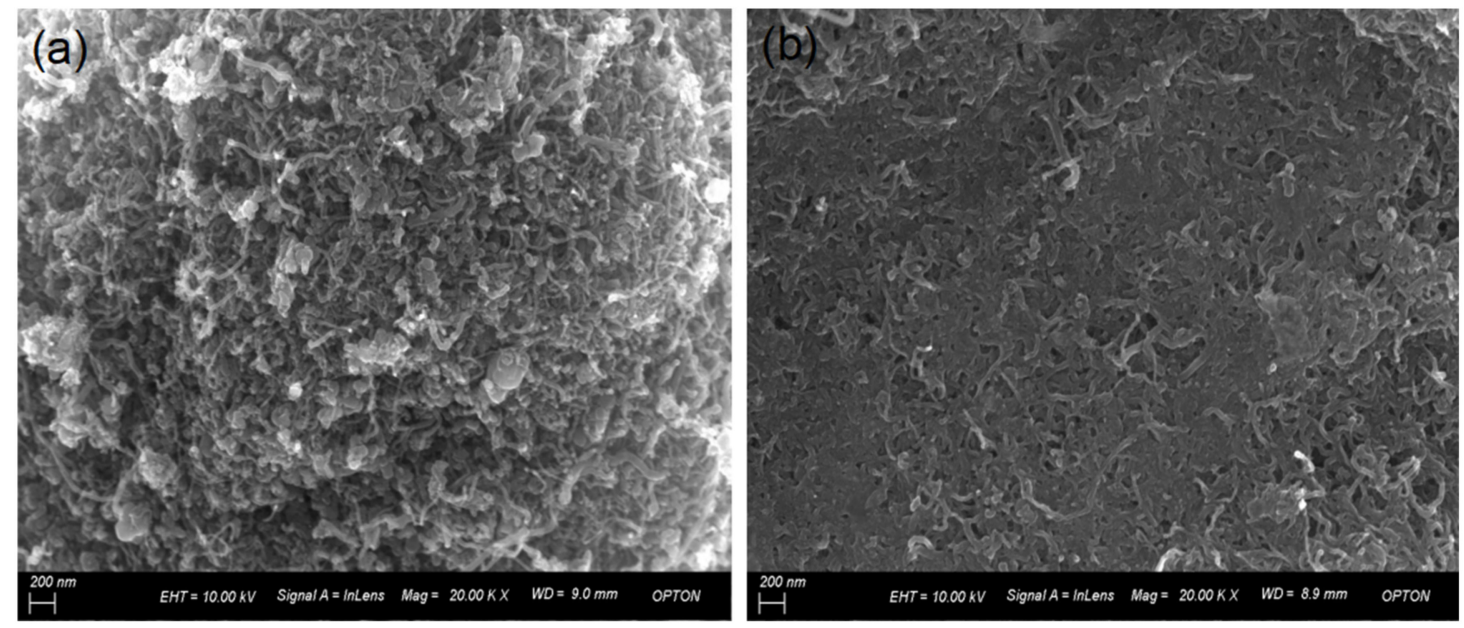

Figure 2. SEM images of the CNTs. (a) pristine CNTs, (b) acid treated CNTs. 

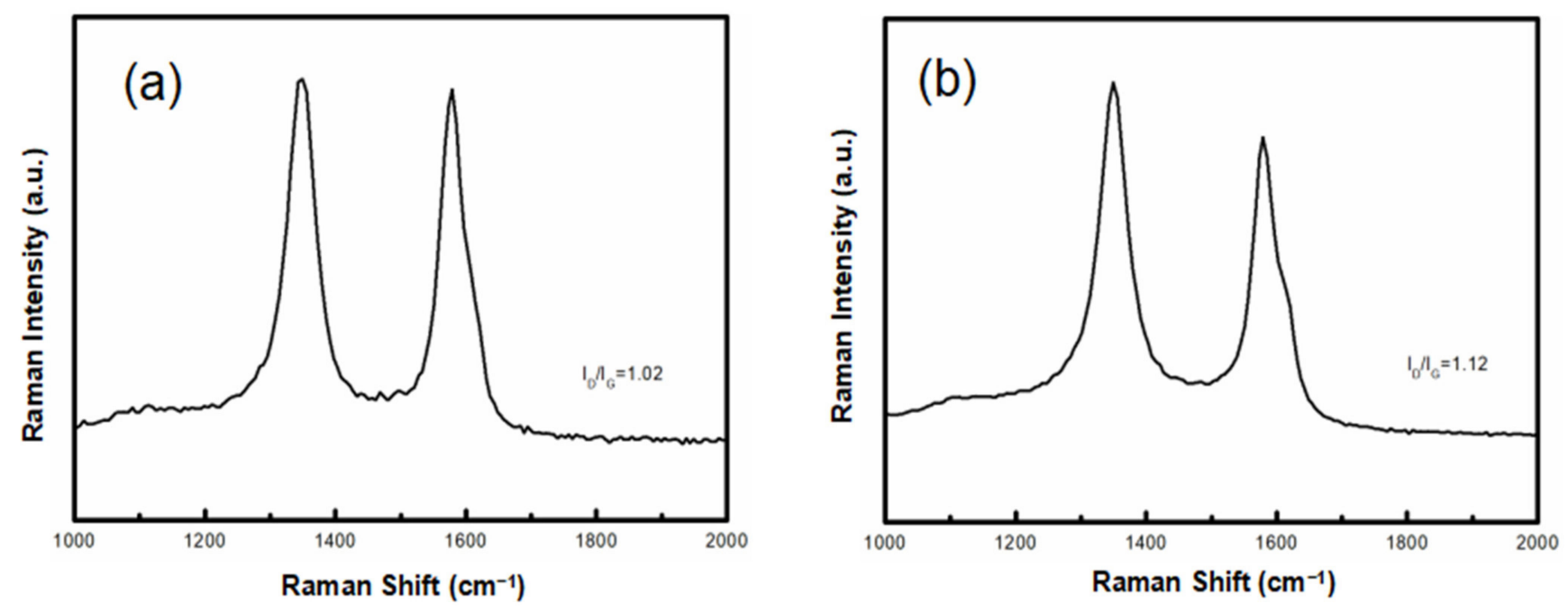

Figure 3. Raman spectra of CNTs. (a) pristine CNTs and (b) surface treated CNTs.

\subsection{Microstructure of Laminated Composite}

Microstructure of the pure magnesium plate after three times of the ARB process was showed in Figure 4. In the RD-ND cross section, the lamellar structure was inapparent, which illustrated that the subsequent rolling was beneficial to the previous combination.

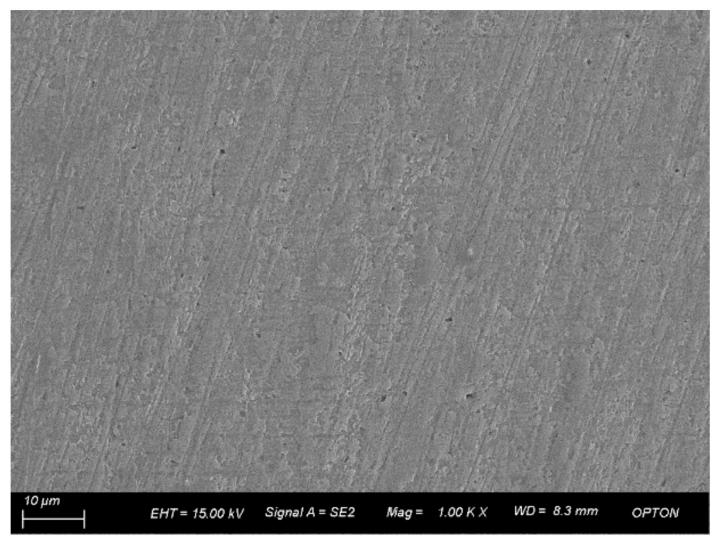

Figure 4. SEM micrographs of the pure magnesium sheet after three times.

Figure 5 illustrated the OM images of composites with different EPD. Through the EPD process and ARB process, the composites were formed into the layered structure. The thickness of the CNTs increased with EPD time, and it could be seen that the ARB process could promote the distribution of CNTs by the way of the shear stress. Figure 6 illustrated the microstructure of EPD 8 min and corresponding magnified figure. From Figure $6 \mathrm{~b}$, it could be seen that carbon nanotubes and magnesium matrix were closely combined, and there were no obvious holes at the interfaces. At the same time, the rolling process could promote dispersion secondarily, in the interfaces, there were some sites where CNTs gathered and some were rare, however, the overall trend was relatively uniform, as shown in Figure 6a. 

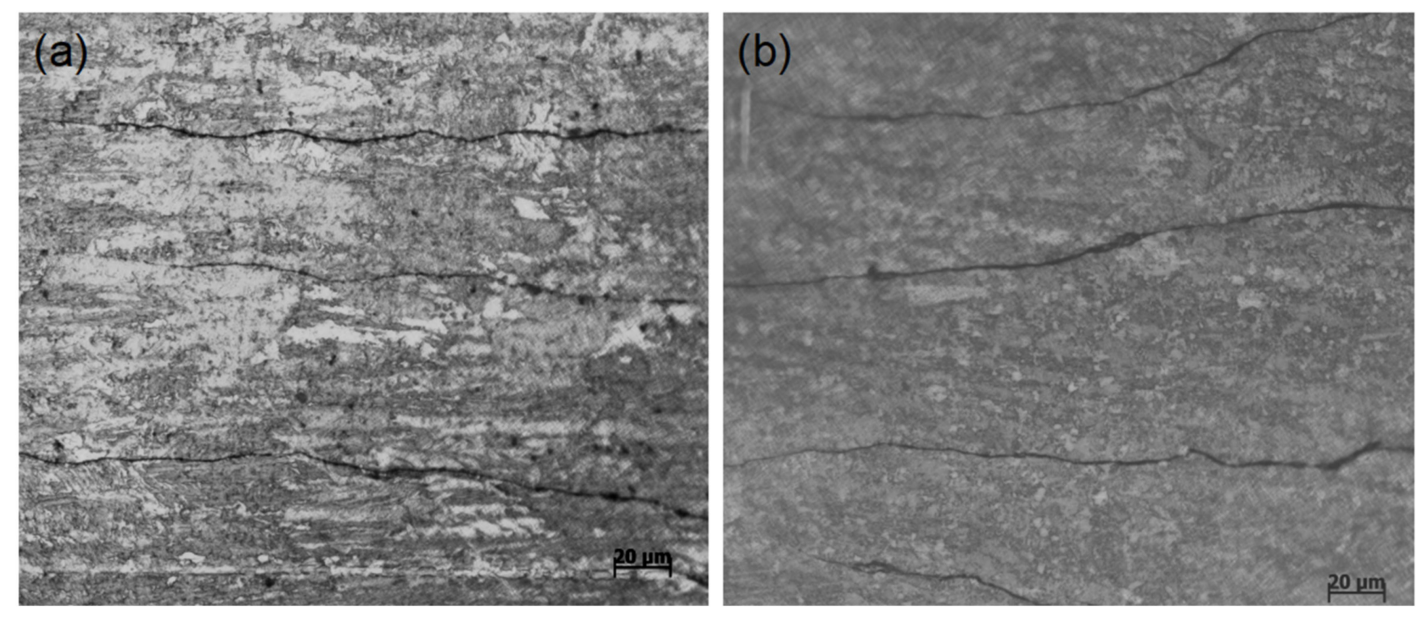

Figure 5. OM micrographs of the ARB process composites microstructures. (a) The EPD 4 min and (b) the EPD 8 min.
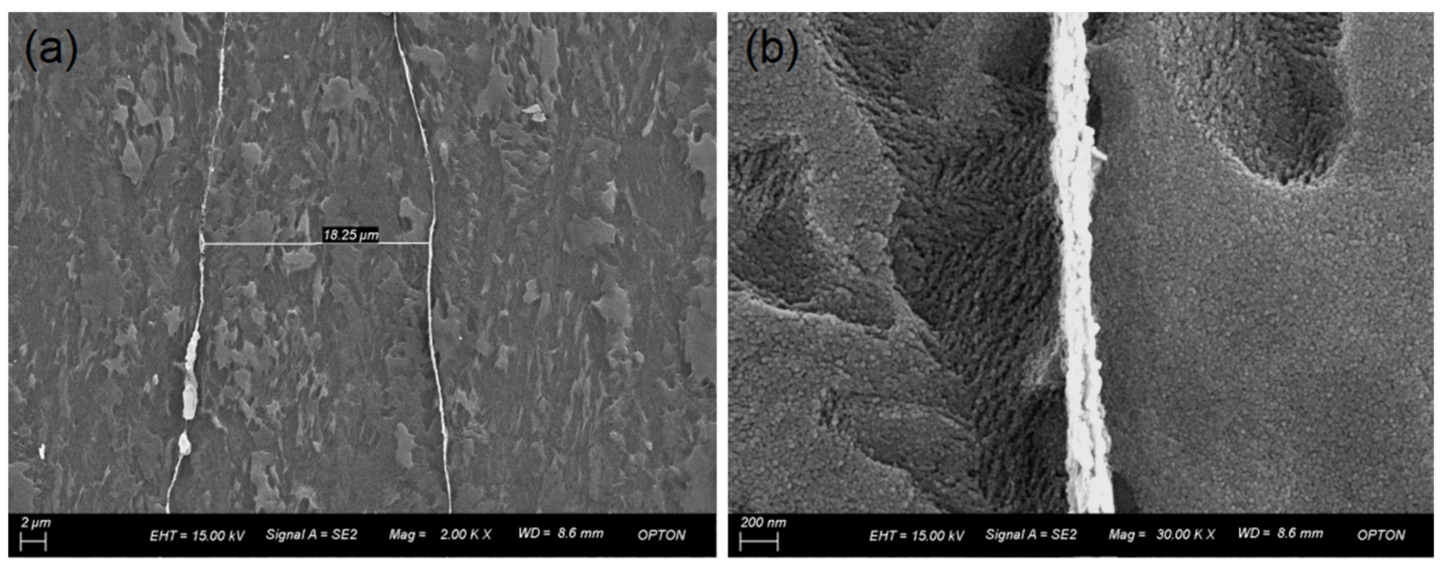

Figure 6. SEM micrographs of the EPD 8 min composites $(\mathbf{a}, \mathbf{b})$ corresponding magnified figure.

Figure 7 displayed the typical XRD patterns of CNTs/Mg matrix composites with different EPD time, the profile for composite included peak which corresponded to the $\mathrm{Mg}$ phase. The peaks of $\mathrm{Mg}-\mathrm{C}$ could not be clearly identified, which indicated that there was no reaction between $\mathrm{Mg}$ and $\mathrm{C}$.

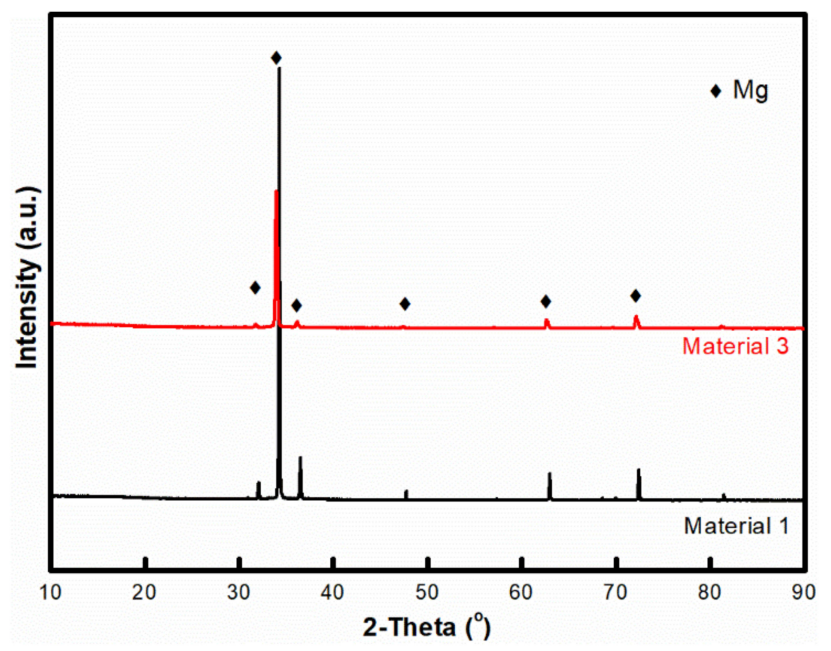

Figure 7. XRD pattern of the ARB process materials. 
From Figure 8, the lamellar structure could be seen at the fracture surface, which indicated that the lamellar structure was formed in the process of ARB. When the electromagnetic wave propagates in the composite materials, these layered structures will provide multilayers reflection in the process of electromagnetic shielding attenuation.
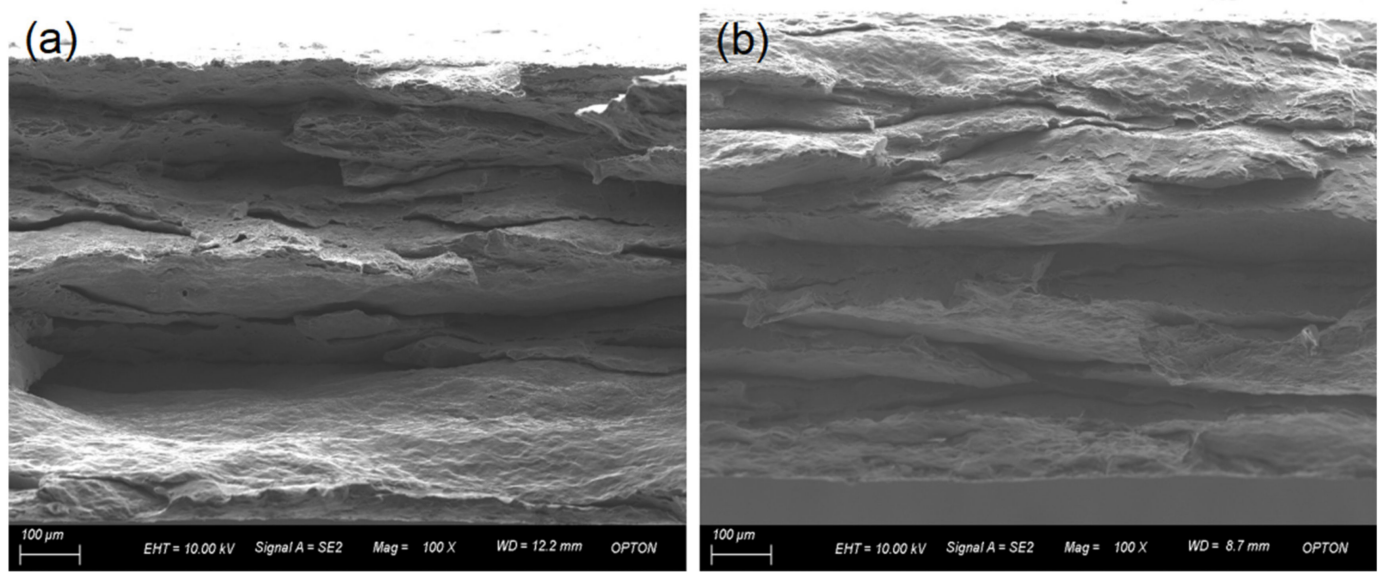

Figure 8. Fracture Surface of the composites. (a) EPD $4 \mathrm{~min}$ and (b) EPD $8 \mathrm{~min}$.

\subsection{Electromagnetic Shielding Properties}

The electromagnetic shielding effectiveness of the CNTs/Mg matrix composites with different EPD times in the X-band were shown in Figure 9. The curves were wavy, which did not show a decreasing trend with the increase of the frequency. The reasons were that the composites were prepared into layered structure and there were the oxidation hardening layer, CNTs in the middle of the composites. The SE value of the pure magnesium after ARB process was 82-92 dB; with the EPD 4 min, the value was $86-94 \mathrm{~dB}$; with increasing EPD $8 \mathrm{~min}$, the composite showed that the value was $87-95 \mathrm{~dB}$. With the increase of the EPD time, the overall EMI shielding performance increased. The EPD process played an obvious effect on the electromagnetic shielding performance. The ARB process can form layered structure and improve electromagnetic shielding performance $[7,11]$. In this experiment, the materials possessed the good shielding performance.

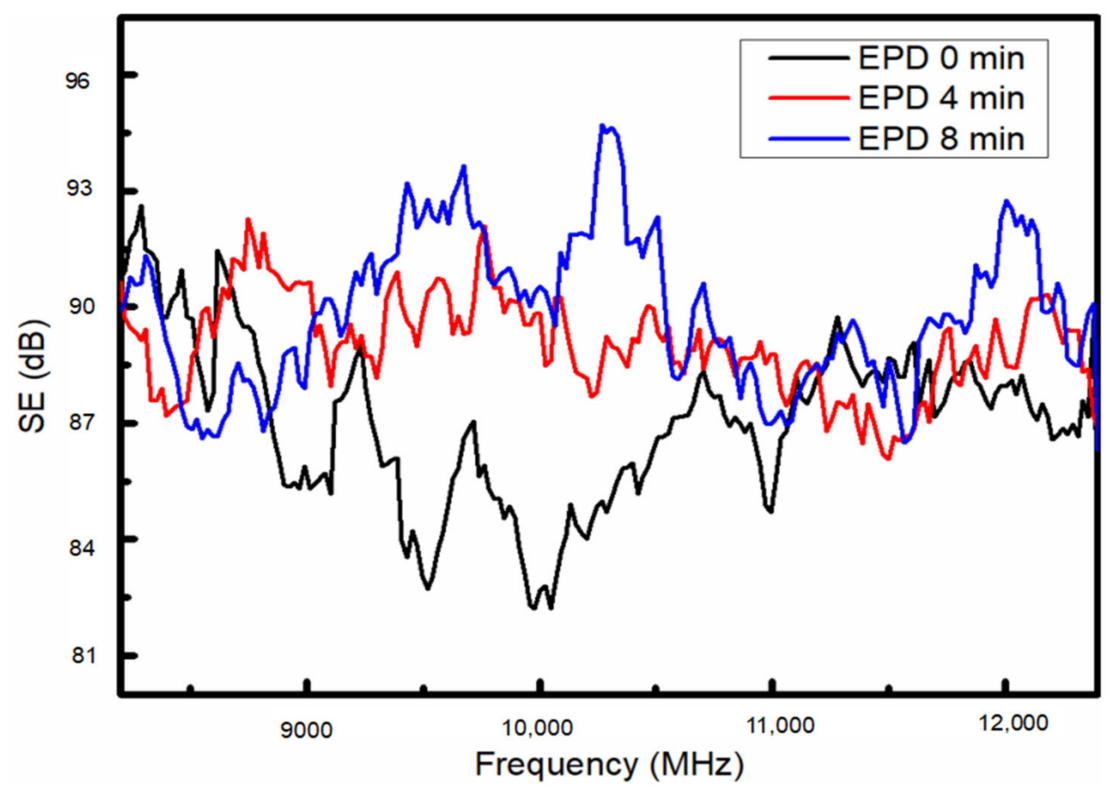

Figure 9. EMI shielding effectiveness of the different EPD time during 8.2-12.4 GHz. 
The layered composites were constructed by the ARB process, and there were some interfaces in the composites. The electromagnetic shielding mechanisms were illustrated in Figure 10. The shielding mechanisms of the composite were special owing to the CNTs between adjacent magnesium layers. Impedance value of magnesium was different from CNTs, so it was necessary to make a detailed analysis of its electromagnetic radiation attenuations.

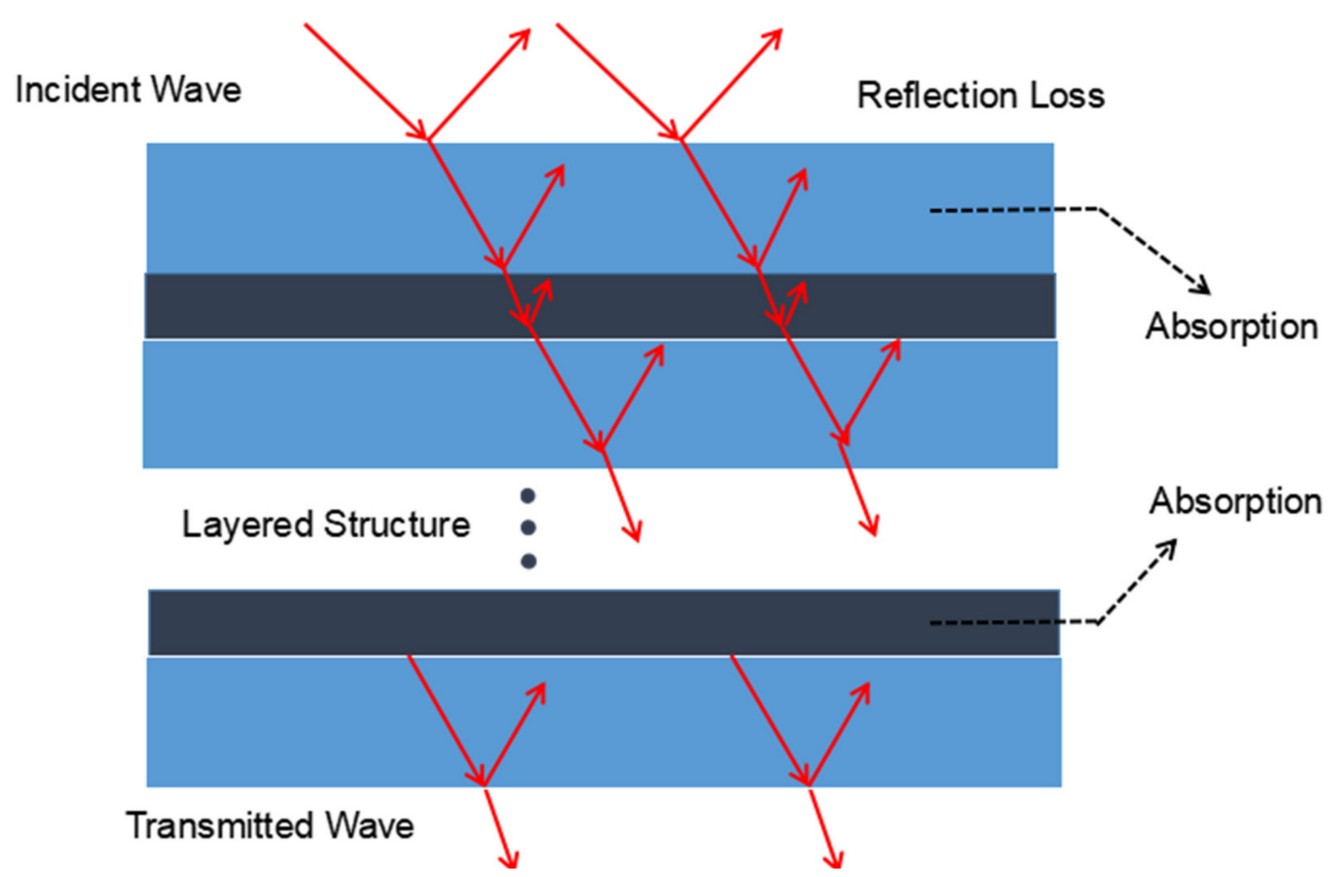

Figure 10. The electromagnetic shielding mechanism of the layered composites.

In the primary, the CNTs in the middle of pure magnesium, with the increase of ARB process, the layered structure with magnesium on both sides and CNTs in the middle was formed. In such a structure, the impedance of adjacent layers was different. When the electromagnetic wave passed through the composites, the special structure provided the multilayer reflection, which contributed to increase the reflection attenuation. At the same time, the interface had a positive effect on the EMI shielding property, which was like "wavy", as shown in Figure 6. The interface could enhance the multiple reflection loss. As is known, the ARB process could refine the grain [28,29], which could introduce the grain boundary in the plates and could also increase the multiple reflection loss, scattering the incident electromagnetic wave.

When the electromagnetic wave incidented on the composites and propagated in the multilayer shielding materials, the shielding property could be enhanced under the synergistic effect of the above factors. The electromagnetic shielding mechanisms of $\mathrm{CNTs} / \mathrm{Mg}$ matrix composites were more complex than that of the magnesium alloy, which were attributed to multilayer-reflection, CNTs-reflection, CNTs-absorption, and so on.

According to the Schelkunoff formula [6], the transmission line analogy is suitable for a conductor flat-type shielding material $[8,11,17]$. When the electromagnetic wave propagates in the prepared materials, we regard the composites as a transmission line, when the electromagnetic wave incident on the material surface from the medium air, owing to the mismatch impedance between the materials and the air, the reflected electromagnetic wave occurred. At the same time, when the transmitted wave propagates in the primary layer of magnesium matrix, there will be absorption loss. Meanwhile, when the transmitted electromagnetic wave reaches the CNTs layer, due to the different impedance between the magnesium and the CNTs, the reflection loss will occur again. Next, the absorption loss will occur in the CNTs. According to this mode, the electromagnetic wave propagates in the composites until it passes through the composites. In order to quantitatively describe 
the shielding performance of the materials, the shielding effectiveness (SE) is used. The total SE value can be expressed by the following formula:

$$
\begin{gathered}
S E(d B)=R+A+B \\
S E_{\mathrm{R}}=20 \lg \frac{|1+k|^{2}}{4|k|}, k=\frac{Z_{\mathrm{m}}}{Z_{0}} \\
S E_{\mathrm{A}}=20 \lg \left(\mathrm{e}^{\frac{t}{\delta_{m}}}\right) \\
S E_{\mathrm{B}}=20 \lg \left(1-\mathrm{e}^{\frac{-2 \mathrm{t}}{\delta_{\mathrm{m}}}}\right) \\
Z_{\mathrm{m}}=3.68 \times 10^{-7} \sqrt{\frac{f \mu_{\mathrm{m}}}{\sigma_{\mathrm{m}}}} \\
\delta_{\mathrm{m}}=\sqrt{\frac{1}{\pi \mu_{\mathrm{m}} \sigma_{\mathrm{m}} f}}
\end{gathered}
$$

where $R, A, B, Z_{\mathrm{m}}, B, \mathrm{Z}_{0}, t, f, \delta_{\mathrm{m}}, \sigma_{\mathrm{m}}, \mu_{\mathrm{m}}$ are reflection loss at the two interface of the shielding material, absorption loss in the body of the shielding material, multiple reflection loss, shield impedance, air impedance $(377 \Omega)$, thickness, electromagnetic radiation frequency, skin depth, electrical conductivity, and magnetic permeability, respectively.

Based on Equations (1), (2) and (5), the EMI shielding capacity of CNTs/Mg depended on the electrical conductivity mainly.

Figure 11 shows the electrical conductivity of the composites with different content of CNTs; the value is $22.07,21.96$ and $21.89 \times 10^{6} \mathrm{~S} / \mathrm{m}$, respectively. As we have learned, in the electromagnetic shielding alloys, the high electrical conductivity converts to high vortex electrical current and the abundant energy of incident wave dissipate in the form of ohmic electrothermal heat, at the same time producing a high reverse electromagnetic field [9]. From Figure 11, the conductivity decreased slightly, but the overall change was not significant. The electrical conductivity declined slightly with the increase of electrophoresis time. The ARB process could introduce oxide layers and other contaminants, which could reduce the conductivity of the materials. However the existence of the CNTs could improve the conductivity, so the change of the conductivity was slight.

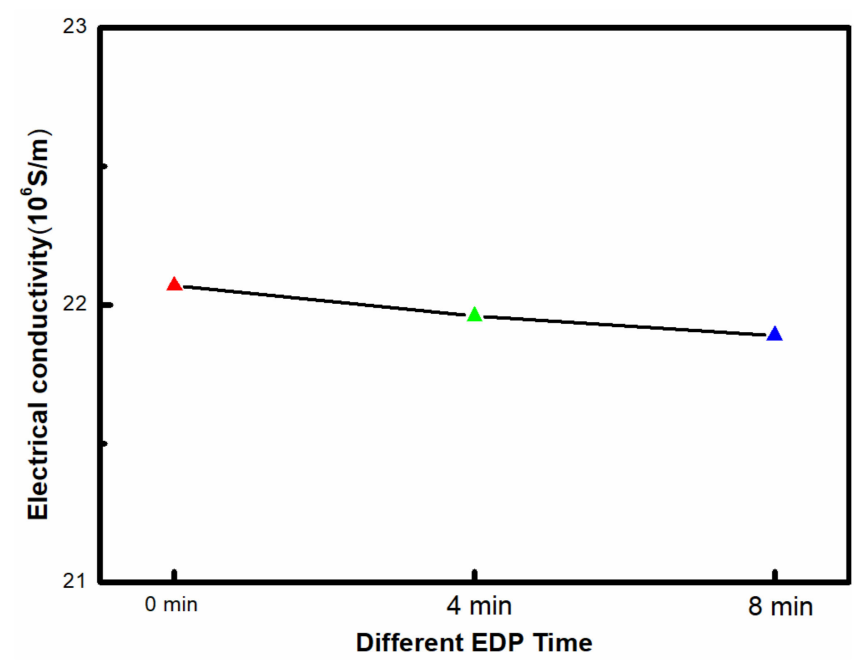

Figure 11. Electrical conductivity of the layered composites with different EPD time.

\section{Conclusions}

1. A new CNTs/Mg matrix laminated composite was prepared by ARB method, which was applied to the field of electromagnetic shielding. 
2. When the EPD time was $8 \mathrm{~min}$, in the testing frequency of $8.2-12.4 \mathrm{GHz}$, the SE value was $85-96 \mathrm{~dB}$. The main shielding mechanism was closely related to the layered structure. Since the impedance of adjacent layers was inconsistent, the layered structure increased the multilayer reflection ability.

3. Oxide layers and other contaminants could be introduced into the interlayer during EPD and ARB process. Due to the existence of CNTs, the electrical conductivity declined slightly, and the value was $22.07,21.96$ and $21.89 \times 10^{6} \mathrm{~S} / \mathrm{m}$, respectively.

\begin{abstract}
Author Contributions: W.Z.: designed the study, performed experiments, analyzed the date, and wrote the manuscript; H.Z. and D.J.: designed the study, analyzed the date, and revised the manuscript; X.H.: per-formed experiments, analyzed the date, and revised the manuscript. All authors have read and agreed to the published version of the manuscript.
\end{abstract}

Funding: This research received no external funding.

Institutional Review Board Statement: Not applicable.

Informed Consent Statement: Not applicable.

Data Availability Statement: The data used to support the findings of this study are available from the corresponding author upon request.

Conflicts of Interest: The authors declare no conflict of interest.

\title{
References
}

1. Fan, Z.W.; Liu, R.T.; Cheng, X.J. Preparation and characterization of electromagnetic shielding composites based on graphenenanosheets-loaded nonwoven fabric. Coatings 2021, 11, 424. [CrossRef]

2. Pan, Y.F.; Yin, D.W.; Yu, X.F. Multilayer-structured wood electroless Cu-Ni composite coatings for electromagnetic interference shielding. Coatings 2020, 10, 740. [CrossRef]

3. Chen, X.H.; Geng, Y.X.; Pan, F.S. Microstructure, mechanical properties and electromagnetic shielding effectiveness of Mg-Y-ZrNd alloy. Rare Met. Mater. Eng. 2016, 45, 13-17.

4. Chen, X.H.; Liu, J.; Pan, F.S. Enhanced electromagnetic interference shielding in ZK60 magnesium alloy by aging precipitation. J. Phys. Chem. Solids 2013, 74, 872-878. [CrossRef]

5. Chen, X.H.; Liu, L.Z.; Liu, J. Microstructure, electromagnetic shielding effectiveness and mechanical properties of Mg-Zn-Y-Zr alloys. Mater. Des. 2015, 65, 360-369. [CrossRef]

6. Song, K.; Pan, F.; Chen, X.; Zhang, Z.; Tang, A.; She, J.; Yu, Z.; Pan, H.; Xu, X. Effect of texture on the electromagnetic shielding property of magnesium alloy. Mater. Lett. 2015, 157, 73-76. [CrossRef]

7. Wang, J.; Xu, L.; Wu, R. Enhanced electromagnetic interference shielding in a duplex-phase Mg-9Li-3Al-1Zn alloy processed by accumulative roll bonding. Acta Met. Sin. Engl. Lett. 2020, 33, 490-499. [CrossRef]

8. Luo, Z.; Chen, X.-H.; Song, K.; Liu, C.-Q.; Dai, Y.; Zhao, D.; Pan, F.-S. Effect of alloying element on electromagnetic interference shielding effectiveness of binary magnesium alloys. Acta Met. Sin. Engl. Lett. 2019, 32, 817-824. [CrossRef]

9. Yang, C.; Pan, F.; Chen, X.; Luo, N. Effects of Sm addition on electromagnetic interference shielding property of Mg-Zn-Zr alloys. Appl. Phys. A Mater. Sci. Process. 2017, 123, 400. [CrossRef]

10. Gao, S.; Chen, X.; Pan, F.; Song, K.; Zhao, C.; Liu, L.; Liu, X.; Zhao, D. Effect of secondary phase on the electromagnetic shielding effectiveness of magnesium alloy. Sci. Rep. 2018, 8, 1-14. [CrossRef]

11. Jian, H.; Qinglong, Z.; Yanxia, N.; Fangkun, N.; Le, Q.; Hou, J.; Zhang, Q.; Niu, Y.; Ning, F. Electromagnetic shielding property of duplex magnesium alloy with laminated structure processed by accumulative roll bonding. Mater. Res. Express 2018, 5, 066533. [CrossRef]

12. Chandra, R.B.J.; Shivamurthy, B.; Kulkarni, S.D.; Kumar, M.S. Hybrid polymer composites for EMI shielding application-a review. Mater. Res. Express 2019, 6, 082008. [CrossRef]

13. Shen, B.; Li, Y.; Zhai, W.T. Compressible graphene-coated polymer foams with ultralow density for adjustable electromagnetic interference (EMI) shielding. ACS Appl. Mater. Interfaces 2016, 8, 8050-8057. [CrossRef] [PubMed]

14. Dziková, J.; Fintová, S.; Kajánek, D.; Florková, Z.; Wasserbauer, J.; Doležal, P. Characterization and corrosion properties of fluoride conversion coating prepared on AZ31 magnesium alloy. Coatings 2021, 11, 675. [CrossRef]

15. Mu, L.; Sun, Q.; Cui, G.; Yuan, S.; Wang, J.; Ma, Z.; Li, M. Preparation and characterization of sustained-release naringin coating on magnesium surface. Coatings 2021, 11, 288. [CrossRef]

16. Wang, S.; Fu, L.; Nai, Z.; Liang, J.; Cao, B. Comparison of corrosion resistance and cytocompatibility of $\mathrm{MgO}$ and $\mathrm{ZrO}_{2}$ coatings on AZ31 magnesium alloy formed via plasma electrolytic oxidation. Coatings 2018, 8, 441. [CrossRef]

17. Liu, L.; Chen, X.; Pan, F.; Wang, Z.; Liu, W.; Cao, P.; Yan, T.; Xu, X. Effect of Y and Ce additions on microstructure and mechanical properties of Mg-Zn-Zr alloys. Mater. Sci. Eng. A 2015, 644, 247-253. [CrossRef] 
18. Liu, L.Z.; Pan, F.S.; Chen, X.H. The effect of Y addition on recrystallization and mechanical properties of Mg-6Zn- $x \mathrm{Y}-0.5 \mathrm{Ce}-0.4 \mathrm{Zr}$ alloys. Vacuum 2018, 155, 445-455. [CrossRef]

19. Liu, L.; Chen, X.; Pan, F.; Tang, A.; Wang, X.; Liu, J.; Gao, S. Microstructure, texture, mechanical properties and electromagnetic shielding effectiveness of Mg-Zn-Zr-Ce alloys. Mater. Sci. Eng. A 2016, 669, 259-268. [CrossRef]

20. Qiao, L.; Zhu, K.L.; Tan, H.S. Effect of carbon nanotubes on the electrical, thermal, mechanical properties and crystallization behavior of continuous carbon fiber reinforced polyether-ether-ketone composites. Mater. Res. Express 2021, 8, 045312. [CrossRef]

21. Yang, S.-Y.; Lin, W.-N.; Huang, Y.-L.; Tien, H.-W.; Wang, J.-Y.; Ma, C.-C.M.; Li, S.-M.; Wang, Y.-S. Synergetic effects of graphene platelets and carbon nanotubes on the mechanical and thermal properties of epoxy composites. Carbon 2011, 49, 793-803. [CrossRef]

22. Yuan, Q.-H.; Fu, D.-M.; Zeng, X.-S.; Liu, Y. Fabrication of carbon nanotube reinforced AZ91D composite with superior mechanical properties. Trans. Nonferr. Met. Soc. China 2017, 27, 1716-1724. [CrossRef]

23. Strozzi, M.; Pellicano, F. Nonlinear resonance interaction between conjugate circumferential flexural modes in single-walled carbon nanotubes. Shock Vib. 2019, 2019, 3241698. [CrossRef]

24. Strozzi, M.; Smirnov, V.V.; Manevitch, L.I. Nonlinear normal modes, resonances and energy exchange in single-walled carbon nanotubes. Int. J. Non-Linear Mech. 2020, 120, 103398. [CrossRef]

25. Giannopoulos, F.; Chronopoulou, N.; Bai, J.; Zhao, H.; Pantelis, D.; Pavlatou, E.; Karantonis, A. Nickel/MWCNT-Al ${ }_{2} \mathrm{O}_{3}$ electrochemical co-deposition: Structural properties and mechanistic aspects. Electrochim. Acta 2016, 207, 76-86. [CrossRef]

26. Mosallanejad, M.H.; Shafyei, A.; Akhavan, S. Simultaneous co-deposition of SiC and CNT into the Ni coating. Can. Metall. Q. 2016, 55, 1-9. [CrossRef]

27. Tseluikin, V.N.; Koreshkova, A.A. Electrodeposition of zinc-nickel-carbon nanotubes composite coatings in a reversing mode. Prot. Met. Phys. Chem. Surf. 2016, 52, 1040-1042. [CrossRef]

28. Chang, H.; Zheng, M.Y.; Xu, C. Microstructure and mechanical properties of the $\mathrm{Mg} / \mathrm{Al}$ multilayer fabricated by accumulative roll bonding (ARB) at ambient temperature. Mater. Sci. Eng. A 2012, 543, 249-256. [CrossRef]

29. Wu, K.; Chang, H.; Maawad, E.; Gan, W.; Brokmeier, H.; Zheng, M. Microstructure and mechanical properties of the Mg/Al laminated composite fabricated by accumulative roll bonding (ARB). Mater. Sci. Eng. A 2010, 527, 3073-3078. [CrossRef]

30. Meng, L.; Wang, X.; Hu, X.; Shi, H.; Wu, K. Role of structural parameters on strength-ductility combination of laminated carbon nanotubes/copper composites. Compos. Part A Appl. Sci. Manuf. 2018, 116, 138-146. [CrossRef]

31. Meng, L.; Wang, X.; Ning, J.; Hu, X.; Fan, G.; Wu, K. Beyond the dimensional limitation in bio-inspired composite: Insertion of carbon nanotubes induced laminated $\mathrm{Cu}$ composite and the simultaneously enhanced strength and toughness. Carbon 2018, 130, 222-232. [CrossRef]

32. Strozzi, M.; Pellicano, F. Linear vibrations of triple-walled carbon nanotubes. Math. Mech. Solids 2018, 23, 1456-1481. [CrossRef]

33. He, X.Q.; Eisenberger, M.; Liew, K.M. The effect of van der Waals interaction modeling on the vibration characteristics of multiwalled carbon nanotubes. J. Appl. Phys. 2006, 100, 124317. [CrossRef]

34. Niu, Y.; Liu, Q.; Yang, J.; Gao, D.; Qin, X.; Luo, D.; Zhang, Z.; Li, Y. Surface-enhanced raman spectroscopy of carbon nanotubes in aqueous solution. Acta Chim. Sin. 2012, 70, 1533-1537. [CrossRef]

35. Wepasnick, K.A.; Smith, B.A.; Bitter, J.L.; Fairbrother, D.H. Chemical and structural characterization of carbon nanotube surfaces. Anal. Bioanal. Chem. 2010, 396, 1003-1014. [CrossRef] 